\title{
Effects of Reaction Conditions on Cobalt-Catalyzed Fischer-Tropsch Synthesis: Interactions between Operating Factors
}

\author{
Hossein Ajamein, Majid Sarkari, Farhad Fazlollahi, and Hossein Atashi* \\ Department of chemical engineering, Faculty of engineering, University of Sistan \& Baluchestan, \\ P.O. Box 98164-161, Zahedan, Iran. E-mail: h.ateshy@hamoon.usb.ac.ir
}

(Received June 19, 2011; Accepted Augsut 19, 2011)

\begin{abstract}
In Fischer-Tropsch Synthesis, because of few reactants $\left(\mathrm{H}_{2}, \mathrm{CO}\right)$, scarce operating parameters affected on efficiency especially the selectivity of products. In this research, effect of operating parameters on the selectivity of $\mathrm{Co}-\mathrm{Mn}^{-\mathrm{TiO}}{ }_{2}$ Fischer-Tropsch synthesis catalyst were studied by design of experimental procedure and Taguchi method. According to this research, interactions between operating factors have a crucial effect on light products selectivity. Among these interactions, (temperature $\times$ feed ratio) has the main influence on light hydrocarbons selectivity. It was concluded that temperature and feed ratio $\left(\mathrm{H}_{2} / \mathrm{CO}\right)$ were the most integral operating parameters for much greater selectivity of light hydrocarbons.
\end{abstract}

Key words: Fischer-Tropsch synthesis, Operating parameters, Taguchi method

\section{INTRODUCTION}

Fischer-Tropsch synthesis (FTS) reaction is a process in which syngas is converted to a variety of products including light gas and heavy hydrocarbons. ${ }^{1}$ Because FTS is a surface reaction, the conversion of synthesis gas over a catalyst is the most noticeable step. As a result, catalyst selection seems to be very important. Recently, Co-Mn catalyst has received enormous attention because of higher olefin and middle distillation cut selectivity. Furthermore, it has been revealed that cobalt based catalysts are specifically greater than iron based catalysts in catalyst life. Another contrast between them is water gas shift reaction that is overlooked in cobalt based catalysts. ${ }^{2,3}$

Dwindling the petroleum reservoirs worldwide and FTS environmental prominence have caused extensive researches on the Fischer Tropsch synthesis. In most cases, they emphasized on catalyst manufacturing and optimization, ${ }^{4,5}$ kinetic modeling, ${ }^{6-8}$ mechanism ${ }^{9}$ and reactor modeling. ${ }^{10,11}$ Meanwhile, a little attention has been allocated to the effect of operating parameters on reactor design and selectivity of products over cobalt based catalysts. Temperature, pressure and feed gas composition have been mainly mentioned as significant effects on selectivity of FTS products. ${ }^{1}$ Dry (1974) declared that temperature effect on selectivity is not manifest and self sufficient. But it depends somewhat on type of catalyst and other process conditions. He implied that if process and catalyst were set up for wax production, an increase in temperature would lower the selectivity of desired product. But for light hydrocarbons, temperature is not an influential factor. He also expressed that gas composition has different effect in diverse situation like temperature. It is the dominant factor to control selectivity for fixed bed wax producing catalysts while the pressure is not important. ${ }^{12}$ Thereafter in 2002, he announced that increasing temperature raises the selectivity of methane in Co-based catalysts. Therefore increasing feed ratio $\left(\mathrm{H}_{2} / \mathrm{CO}\right)$ shifts the selectivity to lighter and more saturated hydrocarbons. ${ }^{13}$

In other research, optimum values for temperature and feed ratio $\left(\mathrm{H}_{2} / \mathrm{CO}\right)$ were proposed due to parabolic trend of products selectivity. In other words, the selectivity of products in lower extent is slight, then it trends to high values and eventually it decreases again. They interpreted that in low temperature due to slight mobility of reactant molecules, most of them have not chance to increase their chain length to convert to methane. But in high temperature they are more energetic and selectivity of long chain products rises as $\mathrm{CH}_{2}$ intermediate production increases. ${ }^{14,15}$

Among these researches, there is no one that probes the optimum values of operating parameters and surveys the effect of interactions between these parameters by experimental design methods. The experimental design is widely used to optimize process parameter values in order to improve the quality properties of a product for example. Conventional experimental design methods are generally complex and do not always reach the desired objectives. Moreover, these methods require a large number of experiments when the number of process parameters increases. ${ }^{16}$ 
Taguchi's method makes use of an experimental process for finding an optimal design. In Taguchi methods, variables or factors are arranged in an orthogonal array (OA) to minimize the number of tests. Taguchi methods can rapidly and accurately acquire technical information to design and produce low-cost, highly reliable products and processes. ${ }^{17}$ Its most advanced applications allow engineers to develop flexible technology for the design and production of families of high quality products, greatly reduce research and development, and delivery time. ${ }^{18}$

In this study an inexpensive and easy-to-operate experimental strategy based on Taguchi's parameter design has been adopted to investigate the effect of various parameters and their interactions. This procedure has been successfully applied for parametric appraisal in different process optimization problems. In addition, the analysis of variance (ANOVA) is done to identify the most signicant control factors and their interactions.

\section{MATERIALS AND METHODS}

\section{Catalyst preparation}

In this research the optimal supported cobalt manganese sample was prepared by co-precipitation method as follows. Aqueous solutions of $\mathrm{Co}\left(\mathrm{NO}_{3}\right)_{3} \cdot 6 \mathrm{H}_{2} \mathrm{O}(0.5 \mathrm{M})(99 \%$, Merck) and $\mathrm{Mn}\left(\mathrm{NO}_{3}\right)_{2} \cdot 4 \mathrm{H}_{2} \mathrm{O}(0.5 \mathrm{M})(99 \%$, Merck) with different molar ratios were pre-mixed and the resulting solutions was heated to $70{ }^{\circ} \mathrm{C}$ in a round bottomed flask fitted with a condenser. Aqueous $\mathrm{Na}_{2} \mathrm{CO}_{3}(0.5 \mathrm{M})$ (99.8\%, Merck) was dropwise added to the mixed nitrate solution with stirring while the temperature was maintained at $70{ }^{\circ} \mathrm{C}$ until $\mathrm{pH} 8 \pm 0.1$ was achieved. The resulting precipitate was then left in this medium for times ranging from 0 to $240 \mathrm{~min}$. The aged precipitate was then filtered and then washed several times with warm distilled water. Then, in order to prepare $\mathrm{TiO}_{2}$ supported catalyst, the optimal amount of $30 \%$ wt of $\mathrm{TiO}_{2}$ based on the total catalyst weight was added to the mixed solution of cobalt and manganese nitrates with the molar ratio of $25 \% \mathrm{Co} / 75 \% \% \mathrm{Mn}$ and then filtered, washed, dried in an oven at $120^{\circ} \mathrm{C}$ for 16 hours to give a material denoted as the catalyst precursor and calcined in static air in a furnace at $500^{\circ} \mathrm{C}$ for 16 hours.

Powder X-ray diffraction (XRD) measurements were carried out using a Bruker axs Company, D8 Advance diffractometer (Germany). The actual phases identified for catalyst precursor were $\mathrm{MnCo}_{3}$ (rhombohedral) and $\mathrm{Co}(\mathrm{OH})_{2}$ (hexagonal), and for calcined catalyst were $\mathrm{Co}_{3} \mathrm{O}_{4}$ (cubic), $(\mathrm{Co}, \mathrm{Mn})(\mathrm{Co}, \mathrm{Mn})_{2} \mathrm{O}_{4}$ (tetragonal), $\mathrm{MnO}_{2}$ (tetragonal and

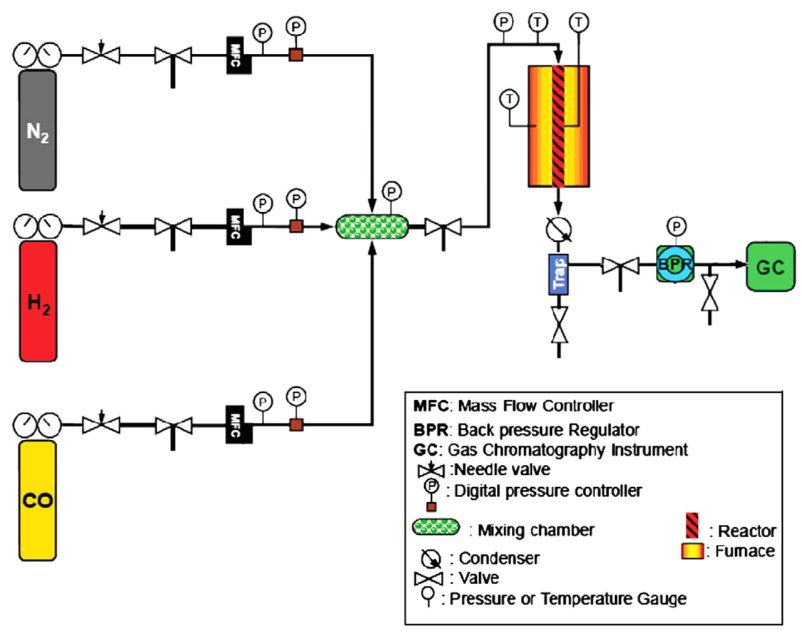

Fig. 1. Schematic diagram of the reactor used.

orthorhombic), $\mathrm{CoMnO}_{3}$ (rhombohedral) and $\mathrm{TiO}_{2}$ (tetragonal).

\section{Catalytic performance}

A schematic representation of the experimental setup is shown in Fig. 1. Fischer-Tropsch synthesis was carried out in a fixed-bed micro-reactor made of stainless steel with an inner diameter of $12 \mathrm{~mm}$. Three mass flow controllers (Brooks, Model, 5850E) were used to adjust automatically flow rate of the inlet gases comprising $\mathrm{CO}, \mathrm{H}_{2}$ and $\mathrm{N}_{2}$ (purity of $99.999 \%$ ). Mixture of $\mathrm{CO}, \mathrm{H}_{2}$ and $\mathrm{N}_{2}$ was subsequently introduced into the reactor, which was placed inside a tubular furnace (Atbin, Model, ATU 15015). Temperature of reaction was controlled by a thermocouple inserted into catalytic bed and visually monitored by a computer. Prior to the catalytic activity measurements, the samples were crushed, sieved (mesh size: 0.1$2.5 \mathrm{~mm}$ ) and then was held in middle of the reactor using quartz wool. The catalyst was in situ pre-reduced at atmospheric pressure under $\mathrm{H}_{2}-\mathrm{N}_{2}$ flow $\left(\mathrm{N}_{2} / \mathrm{H}_{2}=1\right.$, flow rate of each gas $=30 \mathrm{ml} / \mathrm{min}$ ), at $400{ }^{\circ} \mathrm{C}$ for 16 hours. It consists of an electronic back pressure regulator which can control the total pressure of the desired process using a remote control via the TESCOM software package integration that improves or modifies its efficiency that capable for working on pressure ranging from atmospheric pressure to $100 \mathrm{bar}$. In each test, $1.0 \mathrm{~g}$ catalyst was loaded and the reactor operated about 12 hours to ensure steady state operations were attained.

A small portion of the reactor effluent was sent to gas chromatograph (GC) for on-line analysis. The Varian Technologies CP-3400 gas chromatograph equipped with a 10port sampling valve (Supelco Company, USA, Visi Model), 
flam ionization detector (FID) and thermal conductivity detector (TCD) and a capillary column for separating compounds. The contents of sample loop were injected automatically into a packed column (Hayesep DB, Altech Company, USA, 1/8" OD, 10 meters long, and particle mesh 100/120). Helium was employed as a carrier gas for optimum sensitivity (flow rate $=30 \mathrm{ml} / \mathrm{min}$ ). The calibration was carried out using various calibration mixtures and pure compounds obtained from American Matheson Gas Company (USA). GC controlling and collection of all chromatograms were done via an IF-2000 Single channel data interface (TG Co, Tehran, Iran) at windows ${ }^{\circledR}$ environment.

\section{Design of Experiments procedure}

The steps of the Taguchi experimental design are: (a) to select the output variable(s) (response(s)) to be optimized; (b) to identify the factors (input variables) affecting output variable(s) and to choose the levels of these factors; (c) to select the appropriate orthogonal array; (d) to assign factors and interactions to the columns of the array; (e) to perform experiments; at this step it is important to randomize the trials in order to minimize the systematic error; (f) to analyze the results using analysis of variance (ANOVA); (g) to determine the optimal process parameters; (h) to perform conrmatory experiments, if it is necessary. ${ }^{19}$

In this study, Taguchi experimental design was employed for analyzing the influence of operating parameters and their interactions on selectivity of Fischer Tropsch synthesis products. Therefore, 3 control factors were considered: (A) Temperature, (B) pressure and (C) feed ratio $\left(\mathrm{H}_{2} / \mathrm{CO}\right)$. For each factor two levels were chosen. The control factors and their levels are summarized in Table 1. Three interaction between temperature \& pressure $(\mathrm{A} \times \mathrm{B})$,

Table 1. Control factors and their levels

\begin{tabular}{ccc}
\hline Factors & Level 1 & Level 2 \\
\hline A: Temperature & 250 & 260 \\
B: Pressure & 4 & 12 \\
C: Ratio $\left(\mathrm{H}_{2} / \mathrm{CO}\right)$ & 1 & 1.5 \\
\hline
\end{tabular}

temperature \& ratio $(\mathrm{A} \times \mathrm{C})$ and pressure \& ratio $(\mathrm{B} \times \mathrm{C})$ were assessed. According to Taguchi method, the $\mathrm{L}_{8}$ orthogonal array with 3 main factors at 2 levels each and three interactions were adopted for the study. It signifies that Taguchi procedure suggested eight tests for applying the desired responses. Because we wanted to assess the effects of main factors and their interactions on selectivity of methane, ethane, ethylene, propane and propylene as Fischer-Tropsch synthesis products, we had to integrate all responses to one as is explained in. ${ }^{19}$

\section{RESULTS AND DISCUSSIONS}

Two experimental designs were utilized to understand whether interaction effects are important or not. In the first the interaction effects were ignored. So the Taguchi method suggested a $\mathrm{L}_{9}$ orthogonal array matrix for tests. Table 2 shows the $\mathrm{L}_{9}$ matrix and the integral responses for each test for the first design which interaction effects were ignored. By following the Taguchi method steps an ANOVA table for first design was achieved which is illustrated in Table 3.

According to Table 3 the error value is $66.735 \%$ which is much more than the criteria value which is $15 \%$. In such a case, when the error value is more than $15 \%$, it can be concluded that an important factor or interaction effects are disregarded. Therefore in the second design interac-

Table 2. Factor settings for Taguchi $\mathrm{L}_{9}$ design and integrated responses for the first design

\begin{tabular}{ccccc}
\hline \multirow{2}{*}{$\begin{array}{c}\text { Experiment } \\
\text { Number }\end{array}$} & $\begin{array}{c}\text { Factors } \\
\text { Temperature } \\
\text { (A) }\end{array}$ & $\begin{array}{c}\text { Pressure } \\
(\mathrm{B})\end{array}$ & $\begin{array}{c}\text { Feed Ratio } \\
\text { (C) }\end{array}$ & $\begin{array}{c}\text { Integrated } \\
\text { Response }\end{array}$ \\
\hline 1 & 1 & 1 & 1 & 35.74 \\
2 & 2 & 2 & 1 & 31.53 \\
3 & 1 & 3 & 3 & 42.02 \\
4 & 2 & 1 & 2 & 25.62 \\
5 & 2 & 3 & 3 & 27.78 \\
6 & 2 & 3 & 1 & 71.65 \\
7 & 3 & 1 & 3 & 31.77 \\
8 & 3 & 2 & 1 & 40.09 \\
9 & 3 & 3 & 2 & 28.78 \\
\hline
\end{tabular}

Table 3. ANOVA analysis for the first design (without interaction effects consideration)

\begin{tabular}{cccccc}
\hline Factors & DOF & SS & Variance & F-Ratio & P \% \\
\hline A: Temperature & 2 & 111.205 & 55.632 & 0.36 & 0 \\
B: Pressure & 2 & 468.433 & 234.216 & 1.518 & 10.29 \\
C: Ratio $\left(\mathrm{H}_{2} / \mathrm{CO}\right)$ & 2 & 665.373 & 332.686 & 2.156 & 22.97 \\
Error & 2 & 308.493 & 154.246 & - & 66.735 \\
\hline Total & 6 & 1553.504 & & 100 \\
\hline
\end{tabular}


Table 4. Factor settings for Taguchi $\mathrm{L}_{8}$ design and integrated responses

\begin{tabular}{|c|c|c|c|c|c|c|c|c|}
\hline \multirow{3}{*}{$\begin{array}{l}\text { Experiment } \\
\text { Number }\end{array}$} & \multicolumn{7}{|c|}{ Column number, position of the factors, interactions and levels } & \multirow{3}{*}{$\begin{array}{l}\text { Integrated } \\
\text { Response }\end{array}$} \\
\hline & 1 & 2 & 3 & 4 & 5 & 6 & 7 & \\
\hline & A & $\mathrm{B}$ & $\mathrm{A} \times \mathrm{B}$ & $\mathrm{C}$ & $\mathrm{A} \times \mathrm{C}$ & $\mathrm{B} \times \mathrm{C}$ & empty & \\
\hline 1 & 1 & 1 & 1 & 1 & 1 & 1 & 1 & 32.38 \\
\hline 2 & 1 & 1 & 1 & 2 & 2 & 2 & 2 & 35.22 \\
\hline 3 & 1 & 2 & 2 & 1 & 1 & 2 & 2 & 30.98 \\
\hline 4 & 1 & 2 & 2 & 2 & 2 & 1 & 1 & 39.03 \\
\hline 5 & 2 & 1 & 2 & 1 & 2 & 1 & 2 & 64.75 \\
\hline 6 & 2 & 1 & 2 & 2 & 1 & 2 & 1 & 26.1 \\
\hline 7 & 2 & 2 & 1 & 1 & 2 & 2 & 1 & 61.72 \\
\hline 8 & 2 & 2 & 1 & 2 & 1 & 1 & 2 & 27.44 \\
\hline
\end{tabular}

tion effect was exerted.

In this case, the factor settings for Taguchi $\mathrm{L}_{8}$ design and integrated responses are tabulated in Table 4. Now with regard to these responses, the analysis of variance (ANOVA) is applied in order to test the equality of several means, resulting in what process parameters (factors or interactions) are statistically signicant.

The results of ANOVA are presented in a table that displays for each factor (or interaction) the values of:

- $\mathrm{SS}_{\mathrm{i}}$ : sum of squares of each factor.

$$
S S_{i}=\sum_{i=1}^{n} y_{i}
$$

- Total sum of squares $\left(\mathrm{S}_{\mathrm{T}}\right)$ : sum of squared deviations from the mean.

$$
S_{T}=\sum_{i=1}^{n}\left(y_{i}-\bar{y}_{\mathrm{l}}\right)^{2}
$$

- DOF: degree of freedom which is the number of levels for each factor minus 1 .

- Variance: division of sum of squared over degree of freedom of each factor.

$$
V_{i}=\frac{S S_{i}}{D O F_{i}}
$$

- $F$ : $F$ is the ratio between the mean of squares effect and the mean of squares error.

$$
F_{i}=\frac{V_{i}}{V_{\text {Error }}}
$$

F-test is used to see the signicance of each factor (or interaction) on the response variable.

- P: $\mathrm{P}$ is the probability value which gives the degree of condence at which the factor (or interaction) is signicant.

$$
P_{i}=\frac{S S_{i}^{\prime}}{S_{T}}
$$

- Pure Sum $\left(\mathrm{SS}_{\mathrm{i}}^{\prime}\right)$ :

$$
S S_{i}^{\prime}=S S_{i}-\left(V_{\text {Error }}-D O F_{i}\right)
$$

Fig. 2 illustrates the mean average of main factors and interactions. The order of operating parameters and their interaction on the target function is as follows:

1) Interaction $\mathrm{A} \times \mathrm{C}($ Temperature $\times$ Ratio)

2) Ratio $\left(\mathrm{H}_{2} / \mathrm{CO}\right)$

3) Temperature

4) Interaction $B \times C$ (Pressure $\times$ Ratio)

5) Interaction $\mathrm{A} \times \mathrm{B}$ (Temperature $\times$ Pressure)

6) Pressure

In this design the error value of $0.038 \%$ is much lower than the criterion value $15 \%$. So it can be deduced that for this design interaction effects especially $\mathrm{A} \times \mathrm{C}$ have a crucial effect on integrated responses. In ANOVA table, for a degree of freedom of 1 for the numerator (effect) and 1 for the denominator (error), the factor is signicant with $95 \%$ condence if $\mathrm{F}$ exceeds 161.45 , and with $90 \%$ condence for $\mathrm{F}$ higher than $39.864 .{ }^{19}$ Thus, the values of $\mathrm{F}$ in the ANOVA of integrated response for selectivity (Table 4) conrm that the interaction (Temperature $\times$ Ratio), and in a lower extent ratio $\left(\mathrm{H}_{2} / \mathrm{CO}\right)$ and temperature had a significant effect on selectivity as shown in Fig. 2. The result from Taguchi analysis demonstrated the optimum process conditions in Table 5. For this optimum test the evaluated value for integrated response is 65.032 .

\section{CONCLUSIONS}

The effect of operating parameters such as temperature, pressure and feed ratio $\left(\mathrm{H}_{2} / \mathrm{CO}\right)$ on selectivity of light FTS 

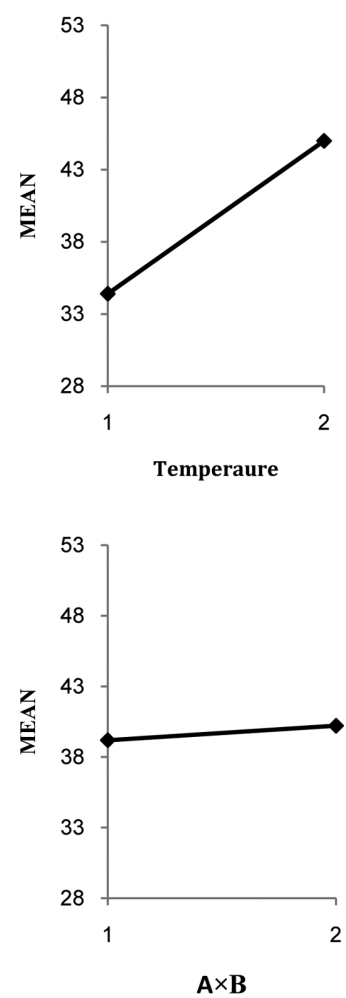
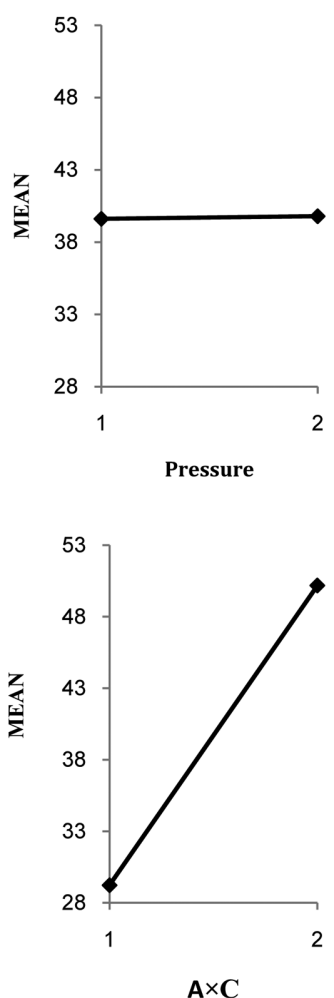
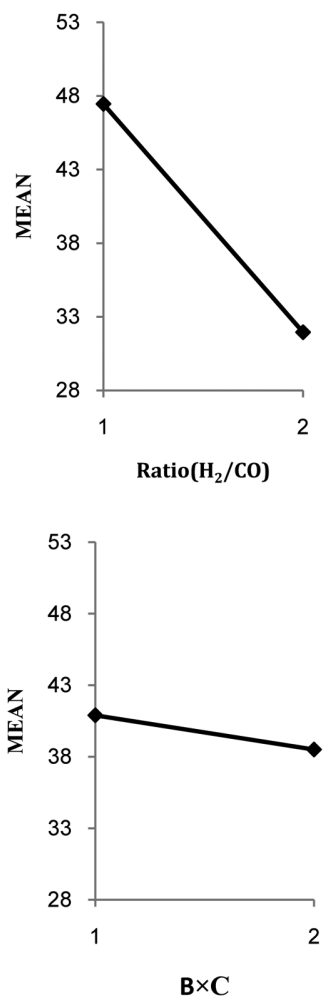

Fig. 2. Analysis of effects of control factors and interactions on mean response.

Table 5. ANOVA analysis

\begin{tabular}{ccccccc}
\hline Factors & DOF & SS & Variance & F-Ratio & Pure sum & P \% \\
\hline A: Temperature & 1 & 224.720 & 224.720 & 2586.926 & 224.633 & 14.059 \\
B: Pressure & 1 & 0.065 & 0.065 & 0.752 & 0.000 & 0.000 \\
$\mathrm{~A} \times \mathrm{B}$ & 1 & 2.101 & 2.101 & 24.195 & 2.014 & 0.126 \\
$\mathrm{C}:$ Ratio $\left(\mathrm{H}_{2} / \mathrm{CO}\right)$ & 1 & 481.120 & 481.120 & 5538.531 & 481.033 & 30.106 \\
$\mathrm{~A} \times \mathrm{C}$ & 1 & 878.224 & 878.224 & 10109.888 & 878.137 & 54.959 \\
$\mathrm{~B} \times \mathrm{C}$ & 1 & 11.471 & 11.471 & 132.056 & 11.384 & 0.712 \\
Error & 1 & 0.086 & 0.086 & & & 0.038 \\
\hline Total & 7 & 1597.790 & & & & 100 \\
\hline
\end{tabular}

Table 6. Optimum operating parameters

\begin{tabular}{cc}
\hline Factors & Level \\
\hline Temperature & 270 \\
Pressure & 12 \\
Ratio $\left(\mathrm{H}_{2} / \mathrm{CO}\right)$ & 1 \\
\hline
\end{tabular}

products were investigated by Taguchi method. From ANOVA table, as a result of Taguchi method, the interaction $\mathrm{A} \times \mathrm{C}($ Temperature $\times$ Feed Ratio) had the main effect on $\mathrm{C}_{2}$ and $\mathrm{C}_{3}$ hydrocarbons selectivity. P-values demonstrate that feed ratio and temperature are the further important parameters. According to the Taguchi method, the best temperature, pressure and feed ratio for the most values of selectivity for light hydrocarbons are $270{ }^{\circ} \mathrm{C}, 12$ bar and $\mathrm{H}_{2} / \mathrm{CO}=1$, respectively.

Acknowledgments. The authors gratefully acknowledge the financial support of this work by University of Sistan and Baluchestan Research Council.

\section{REFERNCES}

1. Steynberg, A. P. Studies in Surface Science and Catalysis, 152; Steynberg, A. P.; Dry, M., Eds.; Elsevier, Amsterdam, 2004.

2. Keyser, M. J.; Everson, R. C.; Espinoza, R. L. Ind. Eng. Chem. 2000, 39, 48.

3. Zakeri, M.; Samimi, A.; Khorram, M.; Atashi, H.; Mirzaei, 
A. Powder Technol. 2010, 200, 164.

4. Keyser, M. J.; Everson, R. C.; Espinoza, R. L. Appl. Catal., A: General. 1998, 171, 99.

5. Feyzi, M.; Irandoust, M.; Mirzaei, A. A. Fuel Process. Technol. 2011, 92, 1136.

6. Atashi, H.; Siami, F.; Mirzaei, A.; Sarkari, M. J. Ind. Eng. Chem. 2010, 16, 952.

7. Sari, A.; Zamani, Y. Sayyed and Taheri, A. Fuel Process. Technol. 2009, 90, 1305.

8. Gideon Botes, F.; van Dyk, B.; McGregor, C. Ind. Eng. Chem. Res. 2009, 48, 10439.

9. H. Davis, B., Catal. Today 2009, 141, 25.

10. Guettel, R.; Turek, T. Chem. Eng. Sci. 2009, 64, 955.

11. Wang,Y. N.; Xu, Y. Y.; Li, Y. W.; Zhao, Y. L.; Zhang, B. J. Chem. Eng. Sci. 2003, 58, 867.
12. Dry, M. E. Ind. Eng. Chem., Prod. Res. Dev. 1976, 15, 282.

13. Dry, M. E. Catal. Today 2002, 71, 227.

14. Mirzaei, A.; Faizi, M.; Habibpour, R. Appl. Catal., A: General. 2006, 306, 98.

15. Mirzaei, A. A.; Habibpour, R.; Faizi, M.; Kashi, E. Appl. Catal., A: General. 2006, 301, 272.

16. Rao, R. S.; Kumar, C. G.; Prakasham, R. S.; Hobbs, P. J. Biothech. J. 2008, 3, 510.

17. Byrne, D. M.; Taguchi, S. Quality Progress. 1987, 20, 19.

18. Antony, J.; Kaye, M.; Frangou, A. TQM Magazine. 1998, 10, 169.

19. Roy, R. K. Design of Experiments Using Taguchi Approach: 16 steps to Product and Process Improvement; John Wiley \& Sons: New York, 2001. 